\title{
HABERMAS E HÖFFE: SOLIPSISMO METÓDICO OU RAZÃO COSMOPOLITA EM KANT?
}

\author{
HABERMAS AND HÖFFE: METHODOLOGICAL SOLIPSISM \\ OR COSMOPOLITAN REASONING IN KANT?
}

\author{
Carlos Willians Jaques Morais ${ }^{1}$
}

\begin{abstract}
RESUMO
O presente trabalho trata de duas perspectivas de interpretação da Crítica da Razão Pura $(K r V)$. Segundo Jürgen Habermas, o esquematismo da razão, medida pela qual se pretende enunciar algum juízo sobre os objetos com a pretensão de fundamentação última do saber, é falso. $\mathrm{O}$ "eu penso" kantiano cai num solipsismo que não o autoriza a estabelecer um vínculo entre verdade e objetividade. $\mathrm{Na}$ perspectiva de Otfried Höffe, o conceito de razão que se apresenta na $\mathrm{KrV}$ merece considerações mais amplas do que aquelas apresentadas por Habermas. Por uma leitura cosmopolítica da $\mathrm{KrV}$ notamos que uma razão republicana tem, por conseguinte, um caráter social e, com isso, antissolipsista. As motivações de Höffe em torno da ideia de República Mundial requerem uma (re)interpretação do papel da razão na $K r V$ a fim de situá-la no projeto filosófico de inspiração republicana e, portanto, cosmopolítica.
\end{abstract}

Palavras-chave: Conhecimento. Solipsismo. Razão Republicana.

\begin{abstract}
This paper deals with two interpretation perspectives of the Critique of Pure Reason $(\mathrm{KrV})$. According to Jürgen Habermas, the schematic reasoning, the measure which seeks to outline some sense about the objects with the intention of complete reasoning, is false. The Kantian "I think" falls into a solipsism that does not allow the establishment of a link between truth and objectivity. From Otfried Höffe's perspective, the concept of reason which is presented in $\mathrm{KrV}$ deserves broader considerations than those presented by Habermas. By a cosmopolitical reading of $\mathrm{KrV}$, it is noticed that a Republican reasoning has, therefore, a social character and, therefore anti-solipsistic. Höffe's motivation around the idea of a World
\end{abstract}

1 Docente do Departamento de Educação da Universidade Estadual de Ponta Grossa. Doutorando em Filosofia e História da Educação pela UNICAMP. Membro do Grupo de Pesquisas Paideia, Linha de Pesquisa Ética e Filosofia Política - FE/UNICAMP. 
Republic requires a (re) interpretation of the role of reason in $\mathrm{KrV}$ to situate it in the philosophical project of republican inspiration, and therefore cosmopolitical.

Keywords: Knowledge. Solipsism. Republican Reasoning.

O Idealismo Transcendental de Kant alcançou certa influência sobre os sistemas filosóficos dos séculos XIX e XX. A subjetividade transcendental e a forma como o entendimento enunciam qualquer juízo sobre os objetos fundam métodos revistos por filósofos que apostam no conhecimento mediante o exercício de parâmetros da consciência. Jürgen Habermas nota com suspeita esse discurso filosófico da Modernidade, com ênfase em Kant, mas sua perspectiva incorre na formação de outra composição da razão. Segundo ele, há um "sintoma de exaustão" sobre as pretensões universalistas da razão que aplicam uma transcendentalidade que não reflete o imanente e não se insere na realidade objetiva. "O paradigma da filosofia da consciência encontra-se esgotado. Sendo assim, os sintomas de esgotamento devem dissolver-se na transição para o paradigma da compreensão".2. Trata-se aqui de uma outra concepção de razão e de uma outra concepção de Filosofia. Na Teoria da Ação Comunicativa ${ }^{3}$, Habermas propõe um conceito forte de Filosofia, entendendo-a como "guardiã da racionalidade". O principal tema da Filosofia é a razão, mas seu processo de fundamentação veio, ao longo da história, a dogmatizá-la ou obscurecê-la, mesmo com o intuito de levá-la ao esclarecimento.

Todos os intentos de fundamentação última em que pervivem as intenções da Filosofia Primeira fracassaram. Nesta situação se põe em marcha uma nova constelação nas relações entre filosofia e ciência. Como demonstra a filosofia da ciência e a história da ciência, a explicação formal das condições de racionalidade e as análises empíricas da materialização e evolução histórica das

\footnotetext{
HABERMAS, J. O discurso filosófico da modernidade [Der Philosophische Diskurs der Moderne]. Trad.: Ana Maria Bernardo et al. Lisboa: Dom Quixote, 1998, p. 277.

3 HABERMAS, J. Teoria de la acción comunicativa: racionalidad de la acción y racionalización social [Theorie des Kommunikativen Handelns: Handlungsrationalität und desellschaftliche Rationalisierung]. Trad. Manuel Jimenez Redondo. Vol. 1. Madrid: Taurus, 1988.; . Teoria de la acción comunicativa: crítica de la razón funcionalista [Theorie des Kommunikativen Handelns: Zur Kritik der funktionalitischen Vernunft]. Trad.: Manuel Jimenez Redondo. Vol. 2. Madrid: Taurus, 1987. Na menção em notas sobre essas obras, serão utilizadas as siglas TAC I para o primeiro volume e TAC II para o segundo, acompanhadas das respectivas páginas.
}

estruturas de racionalidade, se entrelaçam entre si de forma peculiar. As teorias acerca das ciências experimentais modernas se posicionam na linha do positivismo lógico, do racionalismo crítico e do construtivismo metódico e apresentam uma pretensão normativa, por vezes, universalista, que já pode vir respaldada por suposições fundamentalistas de tipo ontológico ou do tipo transcendental ${ }^{4}$.

Habermas aposta numa outra concepção da razão. A razão não é fim (Zweck), mas meio para buscar o entendimento. Dessa maneira, Habermas se situa numa modernidade, cujo projeto encontra-se inacabado. A busca de elementos como a liberdade, a autonomia e a emancipação, passa por uma reformulação racional e, consequentemente, discursiva, das ciências e da moral. Trata-se de uma revisão da racionalidade iluminista e a inserção da racionalidade comunicativa. Essa inserção é inevitável dada a guinada linguística e pragmática da filosofia contemporânea ${ }^{5}$. A razão voltada para o entendimento deve ser compreendida como ação de sujeitos capazes de emitir juízos de valor lógico, moral ou estético e, performativamente, expor seus interesses e estabelecer conclusões no mundo da vida. A racionalidade comunicativa estabelece, portanto, uma noção de sujeito e de mundo.

Não obstante a legitimidade das motivações de Habermas, ainda ocorre uma suspeita sobre as pretensões de validade de seu discurso crítico a respeito dos conceitos de sujeito e de razão apresentados na Crítica da Razão Pura: será possível tratar a filosofia teórica de Kant como a expressão de um solipsismo metódico ou uma reflexão monológica, que se encontra também no Discurso do Método de Descartes, sem as devidas distinções? Höffe defende uma leitura cosmopolítica da Crítica da Razão Pura e aponta os limites da interpretação habermasiana nos caminhos da "destranscendentalização". Tratar a Crítica

\footnotetext{
4 TAC I, p. 17.

OLIVEIRA, M. A. Reviravolta linguístico-pragmática na filosofia contemporânea. São Paulo: Loyola, 1996.
} 
como um processo judicial da razão e da metafísica é a chave de leitura para uma interpretação discursiva e situada historicamente de modo anti-solipsista. Esse é o projeto de uma razão republicana que busca fundamentar a Moral e o Direito segundo seus imperativos de validade universal e democrática ${ }^{6}$.

\section{A crítica de Habermas ao Idealismo Transcendental de Kant}

Habermas mira suas críticas a Kant, na Crítica da Razão Pura ${ }^{7}$. Na primeira parte da obra, onde trata da Dedução Transcendental, Habermas toma atenção sobre todo o formalismo crítico que visa expor o sujeito transcendental enquanto unidade sintética de todo o entendimento. O esquematismo da razão, medida pela qual se pretende enunciar algum juízo sobre os objetos com a pretensão de esclarecimento e progresso do conhecimento científico, é falso. O "eu penso" kantiano cai num solipsismo que não o autoriza a estabelecer um vínculo entre verdade e objetividade. A experiência possível com os objetos requer uma sensibilidade que não se encontra no próprio objeto, mas na consciência do sujeito que regula sua intuição segundo as formas puras do espaço e do tempo. O entendimento, segundo a exposição kantiana, utiliza-se de categorias que também não permitem ao sujeito conhecer a coisa em si, mas apenas o fruto da intuição sensível, apreendida fenomenicamente, e que expressa somente o que a coisa é para o sujeito, sem negar nem afirmar algo, tal como na metafísica de Aristóteles, que Kant tanto criticava. O Idealismo Transcendental de Kant não o habilita a trabalhar com a validação objetiva dos juízos sintéticos. Ao que parece, Kant, que criticou Leibniz por incorrer no erro da anfibologia, também cai nesse equívoco, porém, aos moldes do método que ele mesmo chama de "transcendental". Pois a validação objetiva dos juízos requer, na

\footnotetext{
${ }^{6}$ HÖFFE, Otfried. A democracia no mundo de hoje. Trad.: Tito Lívio Cruz Romão. São Paulo: Martins Fontes, 2005. [Demokratie im Zeitalter Globazierung. München: Beck, 1999].

7 As citações das obras de Kant têm como base a edição da Academia (Kants gesammelte Schriften, organizada pela Preussischen und Deustschen Akademie der Wissenschaften, Berlim, 1902 ss.). O volume da obra citada está em algarismos romanos e as páginas são indicadas em algarismos árabes. As páginas da Crítica da Razão Pura $(\mathrm{KrV})$ são citadas precedidas da letra $\mathrm{A}$, correspondendo à edição de 1781 , e da letra $\mathrm{B}$, referente à edição de 1787; sempre que for transcrita uma numeração seguida destas letras, estamos fazendo referência a esta obra.
}

perspectiva habermasiana, um entendimento situado historicamente no mundo da vida (Lebenswelt).

Na primeira parte da Doutrina Transcendental dos Elementos, Kant expõe os elementos puros da sensibilidade espaço e tempo ${ }^{8}$ que regulam o fenômeno, produto de nossa intuição sensível a respeito dos objetos. Espaço e tempo regulam a intuição sobre os objetos da experiência possível, que permite, sinteticamente, a formulação de qualquer representação. Para Habermas, não há validação objetiva da representação, uma vez que a forma do fenômeno expressa somente o que é o objeto para uma estrutura de consciência (as minhas representações) sem alcançar o próprio objeto enquanto coisa em si (noumenon). Trata-se do entendimento de uma razão que se encontra fora do mundo, que não está situada historicamente e sob determinações sociais.

A objetividade da experiência está, portanto, arraigada na identidade de um substrato natural, na organização corpórea do homem, destinada à ação, e não na unidade originária da apercepção que, segundo Kant, assegura, em absoluto, a identidade da consciência a-histórica com uma necessidade transcendental. Pelo contrário, a identidade dos sujeitos sociais transforma-se com o maior ou menor alcance do seu poder de dispor tecnicamente acerca das coisas. Este ponto de vista é basicamente não-kantiano. O saber engendrado no âmbito do agir instrumental tem na força produtiva sua existência exterior. É por isso que, na relação com o desdobramento das forças produtivas, a natureza civilizada, modificada nos processos de trabalho, altera-se na mesma medida que os próprios sujeitos trabalham. O estágio fático de desenvolvimento das forças produtivas define o plano sobre o qual cada geração deve efetuar novamente a unidade entre sujeito e objeto 9 .

Para Habermas, o problema dos elementos puros da sensibilidade afeta a objetividade das proposições. O processo de fundamentação do conhecimento empregado por Kant pretende reduzir uma aparência de verdade à noção de objetividade, mas sua analítica transcendental não acessa os objetos, pois apenas instrumentaliza a razão para uma ilusão.

No que concerne à lógica transcendental, o uso do entendimento deve se submeter, também, aos

\footnotetext{
8 KrV B 33-73

9 HABERMAS, J. Conhecimento e interesse [Erkenntnis und Interesse] Trad.: José N. Heck. Rio de Janeiro: Zahar, 1982. p. 53.
} 
princípios puros que fundamentam qualquer juízo sobre os objetos. A representação pura vê-se delimitada ao que Kant chama de "tábua das Categorias" (quantidade, qualidade, modalidade e relação) ${ }^{10}$. Qualquer conceito que se pretenda válido precisa passar pela forma desses elementos puros. Kant formula um novo Órganon da razão, e encontra seu mérito enquanto artífice de um novo edifício filosófico, mas seu idealismo transcendental, por outro lado, força uma apreensão dos objetos que não são representados em sua natureza. Ao contrário, o objeto em si nem pode ser conhecido, mas apenas a sua manifestação fenomênica mediante os instrumentos da razão.

As operações sintéticas do sujeito transcendental fazem com que o objeto possa ser pensado, mas introduz uma dicotomia entre o que ele é em si (noumenon) e o que ele é para o sujeito (fenômeno). Sem o quadro conceitual, os objetos não podem ser pensados, embora com ele não pode ser possível uma identidade sujeito-objeto. ${ }^{11}$

No sujeito transcendental encontra-se a síntese originária dos elementos puros do entendimento e da sensibilidade. Estética e lógica transcendentais constituem as condições formais para a unidade necessária da apercepção transcendental: “ $\mathrm{O}$ 'eu penso' formal, que deve preservar a unidade egológica de uma autoconsciência sempre idêntica na pluralidade das representações" "12. Kant sustenta um solipsismo, ou seja, uma autorreflexão monológica do próprio espírito. A razão do sujeito é fim em si mesma e não expõe um conhecimento objetivo do mundo. Seus propósitos de fundamentação última do saber e da metafísica expostos na introdução da Crítica da Razão Pura não são alcançados, não promovendo, portanto, o almejado progresso do conhecimento científico. Os problemas da Filosofia, e particularmente da Metafísica, a que se propôs resolver, tomam uma nova configuração, agora, sob os moldes transcendentais.

Seguindo a crítica que Hegel dirige a Kant, Habermas, em Conhecimento e Interesse ${ }^{13}$, atribui

\footnotetext{
$10 \quad \mathrm{KrV}$ B 95.

11 DURÃO, A. B. A crítica de Habermas à dedução transcendental de Kant. Londrina: Ed. da UEL, 1996, p. 22-3.

12 HABERMAS, J. Pensamento pós-metafísico: estudos filosóficos [Nachmetaphysisches Denken: Philosophische Aufsätze]. Trad.: Flávio B Siebeneichler. 2.ed. Rio de Janeiro: Tempo Brasileiro, 2002, p. 36.

13 Idem. Conhecimento e interesse [Erkenntnis und Interesse] Trad.: José
}

ao sujeito transcendental a noção de um "tribunal da razão" que, mediante a autorreflexão, não procura cientificar-se criticamente, mas busca apenas autocientificar-se, sem, portanto, alcançar experimentalmente o próprio objeto.

Habermas, ao tratar dos "caminhos da destranscendentalização", equipara esses elementos do subjetivismo transcendental ao conceito de "mentalismo" e, sem aprofundar esse conceito, define que o:

Sujeito transcendental é identificado a um Simesmo ou ao Eu. Essa autorreferência, carregada de consequências, parece permitir uma resposta à pergunta fundamental da epistemologia: como é possível o saber (do segundo nível) sobre as condições genéticas do saber empírico (isto é, do saber do primeiro nível)? Tal possibilidade se explica pela autoconsciência, ou seja, pela reflexão sobre mim mesmo como um Si-mesmo capaz de ter representações e objetos. Na medida em que faço de minhas representações de objetos os objetos de outra representação, descubro uma interioridade chamada "subjetividade". ${ }^{14}$

O mundo objetivo é determinado por vivências subjetivas e não possui valor na realidade. É uma visão de mundo solipsista, pois é dada apenas em primeira pessoa. Essa é a moldura categorial do mentalismo kantiano. A histórica tensão entre o ideal e o real não se resolvem em Kant, e assim urge a necessidade de uma outra concepção de razão, de sujeito e de mundo. "Com isto, a tensão transcendental entre o ideal e o real, entre o domínio dos inteligíveis e o das aparências se muda para a realidade social das coordenações de ações e das intuições". ${ }^{15}$ Trata-se de uma transformação da razão "pura" em uma razão "situada"16, como caracteriza Mccarthy ${ }^{17}$, citado por Habermas.

A situação da razão segundo a exposição transcendental de Kant encontra-se no próprio sujeito, em sua própria consciência. Na formulação das representações puras da autoconsciência encontrase "o princípio supremo de todo o conhecimento

\footnotetext{
N. Heck. Rio de Janeiro: Zahar, 1982, p. 36

14 HABERMAS, J. Verdade e justificação: ensaios filosóficos [Wahrheit und Rechtfertigung - Philosophische Aufsätze]. Trad.: Milton Camargo Mota. São Paulo: Loyola, 2004, p.186.

15 Idem. Agir comunicativo e razão destranscendentalizada [Kommunikatives Handeln und detranszendentalisierte Vernunft]. Trad.: Lúcia Aragão. Rio de Janeiro: Tempo Brasileiro, 2002, p. 31

16 Idem

17 MCCARTHY, T. Ideal and illusions. Cambridge (Mass.), 1991.
} 
humano". ${ }^{18}$ Todo o entendimento e qualquer juízo sobre os objetos só são possíveis na medida em que há uma autoafirmação do sujeito, que é origem de todo o pensar. O objeto é sempre objeto para $\operatorname{mim}^{19}$, isto é, são as minhas representações que são formuladas e fundamentadas. O mundo nada mais é, então, do que fruto de minhas representações que, por sua vez, permitem-me autoafirmar como um $a$ priori de pensamento (eu penso).

É por isso que, se o processo de validação do saber passa pelo reconhecimento da subjetividade, a razão atua como um "tribunal". Trata-se de uma postura perigosa frente ao desejo de uma fundamentação que leve ao progresso teórico e científico, uma vez que seus juízos podem se fazer verdadeiros ou falsos universalmente segundo uma consciência individual.

Uma dedução transcendental do sentido categorial de enunciados iria tão-somente abranger uma fundamentação transcendental da verdade das proposições, caso eu pudesse introduzir, na base do idealismo kantiano, um "princípio supremo de todos os juízos sintéticos". Isto não é possível; pois, mesmo para enunciados elementares de observação, a objetividade da experiência só poderia constituir uma satisfatória condição de verdade, se não fôssemos obrigados a entender o progresso científico como uma continuação crítica sucessiva de linguagens teóricas, as quais interpretam de forma sempre "mais adequada" a área-de-objeto constituída à moda pré-científica. Este "ser-adequado" de uma linguagem teórica é uma função da verdade das proposições teóricas, possíveis de serem articuladas com os recursos desta linguagem; se a reivindicação de tais proposições frente à verdade não fosse satisfeita pela argumentação mas, sim, por meio de experiências, o progresso teórico não seria concebível senão como produção de novas experiências. Mais plausível é, em conseqüência, a suposição de que a objetividade de uma experiência não garante a verdade de uma afirmação correspondente, mas apenas a unidade desta experiência na multiplicidade das afirmações, através das quais ela é interpretada ${ }^{20}$. würde eine tranzendentale Begründung der Wahrheit von Aussagen nur einschliebem, wenn ich auf der Grundlage des kantischen Idealismus einen 'obersten Grundsatz aller syntetyschen Urteile' einführen könnte. Das ist nicht möglich; denn die Objetivität der Erfahrung könnte selbst für elementare Beobachtungsaussagen eine hinreichende Wahrheitsbedingung nur dann sein, wenn wir den theoretischen Fortschritt nicht als eine
}

Os juízos expressos em primeira pessoa invocam, segundo a perspectiva habermasiana, um outro problema clássico: a totalidade. Pois o "Eu penso", elemento particular, possui a pretensão de universalidade de seu mundo interior. Isso é contraditório a qualquer sistema de lógica. Ora, somente no âmbito do reconhecimento intersubjetivo do "Eu penso" é que se torna possível atribuir um valor ao mundo objetivo e social. Esse reconhecimento intersubjetivo pressupõe uma outra concepção de razão, e determina a ação como objetivação de um mundo social cuja linguagem visa à construção da racionalidade. Por isso, a postura de Habermas caminha num processo de destranscendentalização da razão, pelo qual é possível o estabelecimento de critérios e exigências de validez naquilo que perfaz o mundo objetivo.

Um "projeto transcendental" em sentido mais fraco é dependente da "transigência". Na dimensão vertical dos referentes mundanos ocorre assim a idealização, em antecipação à totalidade dos referentes possíveis. Na dimensão horizontal das relações que os sujeitos contraem entre si, a suposição de racionalidade recíproca efetuada expressa o que eles, fundamentalmente, esperam uns dos outros. Quando sobretudo o entendimento e a coordenação da ação devem ser possíveis, os atores devem ser capazes de assumir uma posição fundamentada em relação a exigências de validez criticáveis e de se orientarem por exigências de validez na ação própria $^{21}$.

E Habermas contesta as pretensões teóricas de Kant ao afirmar ainda que:

Os sujeitos capazes de linguagem e ação podem se orientar apenas desde o horizonte de seus mundos da vida respectivos para os mundos interiores. Não há referências mundanas puras e simplesmente livres de contextos. Heidegger e Wittgenstein mostraram, cada um a seu modo, que a consciência dos

kritische Fortbildung theorethischer Sprachen, die den vorwissenschaftlich konstituierten Gegenstandsbereich immer 'angemessener' interpretieren, begreifen müßten. Die 'Angemessenheit' einer theoretischen Sätze; würde deren Wahheitsanspruch nicht durch Argumentation eingelöst, sondern durch Erfahrungen, wäre theoretischer Fortschritt nur als Produtiktion neuer Erfahrungen und nicht als neue Intepretation derselben Erfahrungen denkbar. Plausibler ist daher dir Annahme, da $\beta$ die Objetivität einer Erfahrung nicht die Wahrheit einer entsprechenden Behauptung garantiert, sondern nur dir Einheit dieser Erfahrung in der Mannigfaltigkeit der Behauptungen, durch die sie interpretiert wird". HABERMAS, J. Conhecimento e interesse [Erkenntnis und interesse] Trad.: José N. Heck. Rio de Janeiro: Zahar, 1982, p. 350 .

21 HABERMAS, J. Agir comunicativo e razão destranscendentalizada [Kommunikatives Handeln und detranszendentalisierte Vernunft]. Trad. Lúcia Aragão. Rio de Janeiro: Tempo Brasileiro, 2002, p. 55. 
objetos transcendentais de Kant se nutre de abstrações falsas ${ }^{22}$.

Dado o posicionamento crítico de Habermas em relação a Kant e a sua Filosofia Transcendental, torna-se imperativo a exposição dos limites de tais posições. Ao que parece, aquele que sempre criticou a instrumentalização da razão na defesa de interesses privados, lança mão do mesmo recurso para a defesa de sua pragmática universal.

\section{Razão cosmopolita em Kant: Höffe e os limites da crítica habermasiana}

Na perspectiva de Otfried Höffe, o conceito de razão que se apresenta na Crítica da Razão Pura merece considerações mais amplas do que aquelas apresentadas por Habermas. A pragmática da linguagem dirige críticas a uma dimensão restrita do conceito de razão, detendo-se sobretudo, como já vimos, na acusação de solipsismo sobre os termos da apercepção pura e do idealismo transcendental. Assim, seria necessário pensar um processo de "destranscendentalização da razão" enquanto modo de situar a mesma no âmbito da cultura e da sociedade. Nesse caso, o sujeito teórico torna-se um sujeito empírico que, ao interagir com outros sujeitos empíricos, passa a dar validade à suas inferências mediante o uso da linguagem.

Segundo Höffe, tais pressupostos e atribuições são falaciosos, de modo que é preciso repensar tais críticas para podermos defender a ideia de que devemos empenhar uma leitura cosmopolítica da Crítica, ou seja, é necessário entender a obra de Filosofia Fundamental de Kant no contexto do projeto da razão na Terra. Considera-se que contra as equivocadas interpretações (I) não se pode atribuir a Kant um tipo de solipsismo metódico que se encontra na Filosofia do Sujeito de Descartes; (II) o texto da Crítica contém referências políticas que se relacionam a uma leitura cosmopolítica proveniente das motivações de uma razão republicana (motivo textual/filológico); (III) a razão tem um caráter político, pois é ela que deve ter a capacidade de

\footnotetext{
22 Idem, p. 45-6. "Sobre 'a hermenêutica do ser do mundo interior já desenvolvida linguísticamente', cf. "K.O. Apel, Wittgenstein und Heidegger", In: McGuinness, B. et al., Der Löwe spricht ... und Wir Könnem ihn nicht verstehen. Frankfurt a.M, 1991, p.27-8".
}

governar a si mesma. A filosofia deve dominar irrestritamente a "república científica" (B 879), ou seja, a república epistêmica; e (IV) a Crítica é discursiva no sentido que busca reconhecer os alcances e as possibilidades da Metafísica Tradicional não de modo subjetivo e dogmático, mas a partir de um processo judicial (filosófico).

As motivações de Höffe em torno da ideia de República Mundial requerem uma (re)interpretação do papel da razão na Crítica a fim de situá-la no grande projeto arquitetônico de inspiração republicana e, portanto, cosmopolítica.

(I) É comum ouvir entre os críticos da história da filosofia moderna a classificação (rotulação) de conceitos usuais entre filósofos que representam seus respectivos sistemas ou correntes de pensamento. Tais classificações apresentam generalidades que não possibilitam perceber as diferenças existentes entre o que podemos chamar uma "classe de filósofos". Segundo Höffe, incluem-se nesse tipo de reflexão histórica tanto Apel quanto Habermas que, sem os devidos "questionamentos críticos", assumem uma "opinio communnis" ao tratarem indistintamente Descartes, Kant, Weber e até Husserl como os representantes do que chamam de "filosofia da subjetividade" ou "filosofia da consciência", entendendo tais expressões como um paradigma (que teria se esgotado) que incorre num solipsismo que valida qualquer saber a partir da ótica do "Eu penso" (1 $1^{\text {a }}$ pessoa). "Segundo essa crítica do solipsismo, Kant entenderia a razão como uma consciência que capacita para o conhecimento a partir do ponto de vista do indivíduo solitário"23. De antemão é preciso fazer uma diferenciação entre os filósofos e seus respectivos sistemas de pensamento, o que o próprio Kant faz em relação a seus antecessores (assim já percebemos que Kant não permanece na posição do solipsismo). Por uma leitura republicana da Crítica notamos que "uma razão republicana tem, por conseguinte, um caráter social e, com isso, antissolipsista" ${ }^{24}$.

Höffe entende que a pessoa que leva em conta não apenas os interesses privados mas também o bem comum é antissolipsista, e isso é possível notar no que se apresenta praticamente em toda

\footnotetext{
23 HÖFFE, O. Crítica da razão pura: uma leitura cosmo-política. Veritas Porto Alegre, v.48, n. 1, p. 80, 2003.

${ }^{24}$ Idem, p. 81.
} 
a filosofia teórica e prática de Kant (também no período pré-crítico). Dado também que, segundo as variantes lógica e empírica, a razão se constitui por um processo de formação que só é possível realizar mediante intersubjetividade, nota-se uma postura antissolipsista quando a gnosiologia também é uma teoria social que inclui a humanidade inteira.

Kant constrói uma Crítica, e não um Discours de la Méthode, como o faz Descartes. Isso nos permite distinguir claramente a natureza fundamental de suas principais obras: Descartes, um solipsismo metódico; Kant, sua enfática negação desse solipsismo. "Tanto na intenção básica, na disposição geral e no método da Crítica, quanto no teor de suas afirmações, ele defende uma posição claramente anticartesiana e, ao mesmo tempo, antissolipsista"25. Portanto, as críticas de Apel e Habermas merecem uma clarificação e uma reconsideração, de modo a distinguir e a tratar adequadamente o filósofo de Königsberg.

(II) Além disso, o simples fato de a Crítica obter diversas referências políticas já nos faz ensejar uma leitura cosmopolítica sobre seus termos, principalmente quando são apresentados aqueles conceitos que se associam aos fins da própria razão: a liberdade, a moralidade, o bem comum, a paz perpétua e a felicidade. São fins de natureza cosmopolita que somente uma razão republicana é capaz de dirigir.

Mas tais referências, que indicam o filósofo como portador da responsabilidade pelo uso público da razão (Was ist Aufklärung? VIII, 379), formam uma razão de caráter republicano e cosmopolita (III). Mas é preciso relacionar de modo análogo sobre o âmbito desse caráter à Crítica, e, no caso, trata-se daquele espaço de dominação ou governo que Höffe chama de "república epistêmica"26. Assim, formam-se as condições metafísicas e os princípios reguladores da moral, da política e do direito, uma vez a razão prática é reflexo da razão teórica.

Se se compreendem os princípios em um sentido amplo e ao mesmo tempo comparativo, e se tem em mente "todas as proposições gerais" (B 358), então uma ciência positiva do direito pode também preencher o ideal de ciência de Kant. Em sentido estrito, "simplesmente princípios" quer dizer apenas "conhecimentos sintéticos a partir de conceitos', os quais "o entendimento", $<\mathrm{e}>$ também o

\footnotetext{
25 Idem, p. 82.

26 Idem, p.79 apud $\mathrm{KrV}$ B 879
}

entendimento jurídico, "não pode de modo algum fornecer" (B 358). ${ }^{27}$

E ao se entender a Crítica como um processo judicial em que o interrogado (a Metafísica) é obrigado a expor os seus alcances e limites, é apenas no âmbito da discursividade (IV) que a razão possibilita tal entendimento. Tal razão é antissolipsista já que a discursividade pressupõe interação social. A linguagem é a objetivação do uso público da razão (em sentido cosmopolita). E dessa maneira, a leitura cosmopolítica da Crítica permite ainda perceber que tal razão é democrática já que espera um acordo entre cidadãos livres baseado em princípios universais (razão humana universal, B 780).

Entre outros argumentos, Höffe demonstra que as críticas formuladas por Habermas a Kant visam tanto mais a servir de base à composição de sua teoria do agir comunicativo do que a perceber nos limites da racionalidade kantiana suas próprias insuficiências. Logo, o recurso a uma "destranscendentalização da razão", que visa a superar o suposto solipsismo metódico de Kant, funda-se sobre pressupostos falsos e só levantam suspeitas sobre um processo de validação subjetiva nas próprias expressões da "escola" pragmática da linguagem.

\section{Referências}

BAUM, Manfred. Eu lógico e eu pessoal em Kant. Studia Kantiana, v.4, n.1, p.7-26, 2003.

BECK, J. S. Excerto de Erlauternder auszug den Schriften des Herrn Professor Kant (1793-1796). Trad. Ana Maria Benite. In: GIL, Fernando. (Org.). Recepção da crítica da razão pura: antologia de escritos sobre Kant (1786-1844). Lisboa: Fundação Calouste Gulbenkian, 1992, 680p.

BÜHLER, Karl. Sprachtheorie. Sttutgart: Gustav Fischer, 1934.

DURÃO, Aylton Barbieri. A crítica de Habermas à dedução transcendental de Kant. Londrina: Ed. da UEL; Passo Fundo: EDUPF, 1996, 232p.

HABERMAS, Jürgen. Agir comunicativo e razão destrancendentalizada. Trad. Lúcia Aragão. Rio de Janeiro: Tempo Brasileiro, 2002, 111p. Kommunikatives Handeln um destranzendentalisierte Vernunft. Frankfurt am Main: Suhrkamp Verlag, 2001.

\footnotetext{
${ }^{27}$ HÖFFE, O. O imperativo categórico do direito: uma interpretação da "Introdução à Doutrina do Direito". Studia Kantiana, São Paulo, v.1, p.203-236, 1998.
} 
Conhecimento e interesse. Trad. José N. Heck. Rio de Janeiro: Zahar, 1982, 367p. [Erkenntnis und Interesse. Frankfurt am Main: Suhrkamp Verlag, 1973].

O discurso filosófico da modernidade. Trad. Ana Maria Bernardo et al. Lisboa: Publicações Dom Quixote, 1998, 350p. [Der Philosophische Diskurs der Moderne. Frankfurt am Main: Suhrkamp Verlag, 1985].

Pensamento pós-metafísico: estudos filosóficos. Trad. Flávio Beno Siebeneichler. 2. ed. Rio de Janeiro: Tempo Brasileiro, 2002, 271p. [Nachmetaphysisches Denken: Philosophische Aufsätze. Frankfurt am Main: Suhrkamp Verlag, 1988].

Teoria de la acción comunicativa: critica de la razón funcionalista. Trad. Manuel Jimenez Redondo. v.2. Madrid: Taurus, 1987b, 618p. [Theorie des Kommunikatives Handelns: Zur Kritik der funktionalistischen Vernunft. Band 2. Frankfurt am Main: Suhrkamp Verlag, 1981].

Teoria de la acción comunicativa: racionalidad de la acción y racionalización social. Trad. Manuel Jimenez Redondo. v. 1. 4. ed. Madrid: Taurus, 1987a, 517p. [Theorie des Kommunikatives Handelns: Handlungsrationalität und gesellschaftliche Rationalisierung. Band 1. Frankfurt am Main: Suhrkamp Verlag, 1981].

Verdade e justificação: ensaios filosóficos. Trad. Milton Camargo Mota. São Paulo: Loyola, 2004, 330p. [Wahreit und Rechtfertigung: Philosophische Aufsätze. Frankfurt am Main: Suhrkamp Verlag, 1999].

HÖFFE, Otfried. A democracia no mundo de hoje. Trad.: Tito Lívio Cruz Romão. São Paulo: Martins Fontes: 2005. [Demokratie im Zeitalter Globazierung. München: Beck, 1999].

Crítica da razão pura: uma leitura cosmo-política. Veritas. Porto Alegre. vol. 48, n. 1. Mar 2003, p. 77-97.

O imperativo categórico do direito: uma interpretação da "Introdução à Doutrina do Direito". Studia Kantiana. v.1. São Paulo, 1998, p. 203-236.

Visão república mundial: democracia na era da globalização. Veritas. Porto Alegre. vol. 47, n. 4. dez 2003, p. 553-566.

KANT, I. Crítica da razão pura. [Kritik der reinen Vernunft]. Trad. Valério Rohden e Udo Baldur Moosburger. 2. ed. São Paulo: Abril Cultural, 1983, 415p.

Resposta à pergunta: o que é o esclarecimento? [Beantworten der Frage: Was ist Aufklärung?]. In: Textos seletos. Trad. Raimundo Vier. 2. ed. Petrópolis: Vozes, 1985, p. 100-117.

McCARTHY, Thomas. Ideal and illusions. Cambridge: MIT Press, 1991.
MCGUINNESS, B. et al., Der löwe spricht... und Wir Könnem ihn nicht verstehen. Frankfurt a.M.: Suhrkamp, 1991. p.27-8.

OLIVEIRA, Manfredo Araújo. Reviravolta lingüísticopragmática na filosofia contemporânea. São Paulo: Loyola, 1996, 427p. 